\title{
Scabies in Children: A Retrospective Study
}

\author{
Retha, Sawitri \\ Departement of Dermatology and Venereology \\ Faculty of Medicine Universitas Airlangga/Dr. Soetomo General Academic Teaching Hospital \\ Surabaya
}

\begin{abstract}
Background: Scabies is a skin disease in humans and is caused by Sarcoptes scabiei mite. It burrows into the skin and is transmitted through close physical contact. The common symptom is itchiness, mainly occur at night, along with a history of itch from family members or friends with whom the patients might have close physical contact before. Scabies is still a concerning health problem for the majority of poor and developing countries. Purpose: To evaluate the profile of newlyadmitted children scabies patients. Methods: This study retrospectively evaluated the medical records of subjects with scabies in the Children Dermatology Division, Dermatology and Venereology Department of Dr. Soetomo General Academic Hospital, Surabaya, between January 2012 and December 2014. Results: There were 545 patients with scabies (33.6\% from Children Dermatology Division visit and 3.2\% from overall outpatient clinic visit), mainly consisted of children aged 5-14 years old (69\%), and mostly males (62.6\%). The most common symptom was itchiness (70.28\%), most patient sought treatment after the complaint have been persisted for more than 30 days $(51.7 \%)$, and $66.4 \%$ patients have family members with similar complaint. Most of the lesions were found on the hands (60.37\%), mostly as papules (73.2\%). Almost all of them did not undergo a skin scraping examination (99.1\%). The most common therapy combination was permethrin $5 \%$ and oral antihistamine $(49.7 \%)$. Conclusions: This profile on scabies patients was expected to aid in improving scabies treatment in the future.
\end{abstract}

Key words: scabies, children, retrospective.

Correspondence address: Sawitri, Department of Dermatology and Venereology, Faculty of Medicine, Universitas Airlangga, Dr. Soetomo General Academic Teaching Hospital, J1. Prof. Dr. Moestopo Street No. 6-8 Surabaya 60131, Indonesia. Phone: +623 5501609, e-mail: sawitri.rh@gmail.com.

\section{INTRODUCTION}

Scabies is a common parasitic infection disease and is caused by Sarcoptes scabiei var. Hominis mites. The infestation begins when the mite burrows into the skin. It occurs as a very itchy skin lesion in the forms of papules, nodules, vesicles, burrows, that can develop into skin erosion, excoriation, and eczematous. ${ }^{1}$

A study by Romani et al., through 48 scabies studies, shows that the highest prevalence was found in Papua New Guinea (71\%). Children in developing countries are the most vulnerable to this disease, with a prevalence of about 5-10\%. Two retrospective studies by Kartika Paramita between 2009 until 2011 in the outpatient clinic of Dermatology and Venereology Department of Dr. Soetomo General Academic Hospital, Surabaya, revealed that the prevalence of scabies in children was $5.9 \%$ of all patients in the Children Dermatology Division. ${ }^{3}$

Scabies is endemic in the tropics and subtropics area such as Africa, Egypt, Central, and Southeast America, Caribbean Islands, India, and Southeast Asia. In industrial countries, scabies is sporadically found as individual cases. An epidemiological study indicates that the prevalence of scabies is not affected by sex, race, age, or socioeconomic status. The main contributor to its transmission is poverty and a dense living environment. ${ }^{1}$

The mite's life cycle wholly takes place on the human skin. Female mites are able to chew and dig burrows on the stratum corneum down to the margins of the granular layer. The females lay about 3 eggs daily along the trails-sometimes reaching $1 \mathrm{~cm}$ in length during its 4 to 6-week lifespan. However, less than $1 \%$ of the eggs thrive in the end. These eggs hatch within 3 to 4 days before the larvae leave the burrow and grow into adult mites on the skin surface. The development stages include egg, larvae, protonymph, and tritonymph. It is under discussion that the male mites live on the skin surface, enter the burrows to mate, and die soon after. ${ }^{1}$ The skin eruption following the infection is considered as a result of mite infestation and hypersensitivity reaction to scabies mites. ${ }^{4}$

Pruritus is the most apparent manifestation following a scabies infection, which is usually getting worse at night. The symptom commonly occurs within 4-6 weeks after the first infestation, while 
recurring infestation occurs within 2 days. Just as humanly response to other types of insects such as fleas, "yellow jackets", and mosquitoes, there is a huge difference between a clinical response following scabies infestation and a number of asymptomatic individuals despite the infestation. These individuals are called "carriers". 5,6

Examination findings include erythematous papulovesicular lesion, excoriation, and eczematous dermatitis that are typically found on interdigital membranes, sides of the fingers, the volar plate of the wrist, and the lateral plane of the palm, elbow, axillae, scrotum, penis, labia, and areolae in women. The head and neck are not usually involved in healthy adults, although any skin surface might be involved in infants, elders, and immunocompromised individuals. Indurated, crusted nodules might be found on the intertriginous planes in children. ${ }^{1,5,7}$

The diagnosis of scabies is based on clinical manifestations and microscopical findings. Lesionfinding is often difficult to do as it is usually already covered and mixed with eczema or impetigo. A presumptive diagnosis can be made based on a typical history of pruritus that worsens at night, its lesion distribution, and a history of contact with other scabies patients. ${ }^{1}$

The exact diagnosis is made through microscopic identification of the scabies mites, eggs, eggshell remnants, or faeces (scybala) scraped from the skin papule or under the nails. One or two drops of mineral oil are dropped on the burrows followed by careful longitudinal scraping along the trace with a scalpel number 15 to avoid bleeding. The scraped skin is put on an object-glass and evaluated under the microscope using low light. ${ }^{6}$ The resulting diagnosis by skin biopsy is then used to confirm if there is evidence of mites or remnants of it. Otherwise, the diagnosis is based on clinical findings and epidemiology. ${ }^{1}$

Epiluminescence microscope and dermatoscope video with high resolution are non-invasive techniques, enabling a clearer inspection of the subject's skin from the outer layer to the papillary dermis. These technologies aid the diagnosis when a "jet-with-contrail" pattern is evident, which marks the presence of mites and its burrows. As it is sometimes difficult to collect skin scrape from a number of subjects such as infants, as well as the low sensitivity of the classical method, dermatoscope might help the diagnosis. Yet, it still lacks in cohort study due to the tool's high cost. ${ }^{6}$

Scabies is treated with a combination of scabicide and fomite control. This insecticidal therapy is usually reapplied one week after the first application and is aimed to reduce the fomite's potency and eradicate nymphs that might hatch after the first therapy due to the environmental protection to the egg. All household members and close contacts must be treated as well-simultaneously-to prevent reinfestation from asymptomatic carriers. ${ }^{6}$

Topical scabicide such as permethrin $5 \%$ is applied in one night onto the skin, especially on the hands and feet fingers, the cleft of the buttocks, navel, and under the nails of the fingers. In adults, the face and scalp can be left bare. Most patients report symptom-free within 3 days; however, it is important to inform that the rashes and pruritus might still be there despite adequate therapy for up to 4 weeks. The itch during this period is called "post-scabetic itch". The patients should be educated that the use of harsh/strong soap might further worsen the skin irritation. Oral antihistamines and emollients might be advantageous. $^{6}$

The 2-4 ointment is also used in Indonesia to treat scabies. This ointment contains $2 \%$ salicylic acid and $4 \%$ sulphur. Salicylic acid is the oldest-known keratolytic substance for topical application. Sulphur has anti-seborrheic, anti-acne, and anti-scabies features. In this case, precipitated sulphur is regularly used. However, this preparation is ineffective against the eggs, therefore it should not be used for less than 3 days. ${ }^{8}$

Scabies infestation makes a port of entry for bacteria. Moreover, the complementary inhibitor of the scabies mites promotes in vitro bacterial growth. Consequently, a secondary bacterial infection often follows in the form of impetigo, cellulitis, and abscess. These conditions might further develop into more severe infections, namely post-streptococcal glomerulonephritis from scabies-induced pyoderma due to Streptococcus pyogenes, more invasive infections, and sepsis. Lymphangitis and septicaemia have also been reported in crusted scabies cases. Scabies infestation might also trigger bullous pemphigoid. $^{2,6,9}$ The right treatment and education can cure scabies. However, scabies is still common. Therefore, this retrospective study was conducted to describe the characteristic of children scabies patient.

\section{RESEARCH METHODS}

This retrospective study evaluated the medical records of newly-diagnosed scabies patients at the Children Dermatology Division in the outpatient clinic of the Dermatology and Venereology Department of Dr. Soetomo General Academic Hospital, Surabaya between 2012 and 2014. From the medical records, basic data, anamnesis, examinations, and treatments were collected and then processed. 


\section{RESULTS}

There were 545 patients with scabies admitted to the Children Dermatology Division in the outpatient clinic of the Dermatology and Venereology Department of Dr. Soetomo General Academic Hospital, Surabaya, between 2012 and 2014.

The youngest admitted patients at the Children Dermatology Division in the outpatient clinic of Dermatology and Venereology Department of Dr. Soetomo General Academic Hospital, Surabaya between 2012 until 2014 were 2 months old, while the oldest was 14 years old. The major distribution was 514 years old age group, which was 377 patients
$(69 \%)$. The patients were dominated by males. There were a total of 341 male patients $(62.6 \%)$ and 204 female patients $(37.4 \%)$ with a 1.7:1 ratio.

Most patients at the Children Dermatology Division in the outpatient clinic of Dermatology and Venereology Department of Dr. Soetomo General Academic Hospital, Surabaya, between 2012 and 2014, presented with itchiness as the main complaint which worsens at night; there were 383 patients (70.28\%). There were 282 patients $(51.7 \%)$ sought treatment about 30 days after the symptom, and 49 patients (9\%) sought treatment after 15-30 days.

Table 1. The age distribution of scabies patients in the Children Dermatology Division in the outpatient clinic of Dermatology and Venereology Department of Dr. Soetomo General Academic Hospital, Surabaya, from 2012 to 2014

\begin{tabular}{|c|c|c|c|c|}
\hline \multicolumn{5}{|c|}{ Year } \\
\hline Age group & $2012(\%)$ & $2013(\%)$ & $2014(\%)$ & Total (\%) \\
\hline $0-1$ year & $18(9,1)$ & $18(9,4)$ & $14(9,0)$ & $50(9)$ \\
\hline $1-4$ years & $47(23,9)$ & $29(15,1)$ & $42(26,9)$ & $118(22)$ \\
\hline $5-14$ years & $132(67,0)$ & $145(75,5)$ & $100(64,1)$ & $377(69)$ \\
\hline Jumlah & $197(100)$ & $192(100)$ & $156(100)$ & $545(100)$ \\
\hline
\end{tabular}

Table 2. The sex distribution of scabies patients in the Children Dermatology Division in the outpatient clinic of Dermatology and Venereology Department of Dr. Soetomo General Academic Hospital, Surabaya, from 2012 to 2014

\begin{tabular}{lrrrr}
\hline & \multicolumn{4}{c}{ Year } \\
Sex & $2012(\%)$ & $2013(\%)$ & $2014(\%)$ & Total $(\%)$ \\
\hline Male & $124(62,9)$ & $122(63,5)$ & $95(60,9)$ & $341(62,6)$ \\
Female & $73(37,1)$ & $70(36,5)$ & $61(39,1)$ & $204(37,4)$ \\
\hline Total & $197(100)$ & $192(100)$ & $156(100)$ & $545(100)$ \\
\hline
\end{tabular}

Table 3. The main complaint of scabies patients in the Children Dermatology Division in the outpatient clinic of Dermatology and Venereology Department of Dr. Soetomo General Academic Hospital, Surabaya, from 2012 to 2014

\begin{tabular}{|c|c|c|c|c|}
\hline \multirow[t]{2}{*}{ Anamnesis } & \multicolumn{3}{|c|}{ Year } & \multirow[t]{2}{*}{ Total $(\%)$} \\
\hline & 2012 & 2013 & 2014 & \\
\hline \multicolumn{5}{|l|}{ Main complaint: } \\
\hline Itchiness & 138 & 130 & 115 & $383(70.28)$ \\
\hline Vesicles & 30 & 20 & 10 & $60(11.01)$ \\
\hline Papules & 4 & 21 & 30 & $55(10.09)$ \\
\hline Itchiness + vesicles & 20 & 7 & 4 & $31(5.69)$ \\
\hline Itchiness + papules & 3 & 7 & 11 & $21(3.85)$ \\
\hline Vesicles + papules & 1 & 5 & 2 & $8(1.47)$ \\
\hline Itchiness + vesicles + papules & 1 & 2 & 2 & $5(0.92)$ \\
\hline \multicolumn{5}{|l|}{ Duration of complaint: } \\
\hline $1-7$ days & 34 & 42 & 44 & $120(22)$ \\
\hline$>7-14$ days & 34 & 36 & 24 & $94(17.3)$ \\
\hline$>14-30$ days & 24 & 15 & 10 & $49(9)$ \\
\hline$>30$ days & 105 & 99 & 78 & $282(51.7)$ \\
\hline
\end{tabular}


There were 362 scabies patients $(66.4 \%)$ presented at the Children Dermatology Division in the outpatient clinic of Dermatology and Venereology Department of Dr. Soetomo General Academic
Hospital, Surabaya, between 2012 and 2014 with a history of similar symptom from their family members. There were 123 patients $(22.6 \%)$ with no source of transmission.

Table 4. The source of transmission of scabies patients in the Children Dermatology Division in the outpatient clinic of Dermatology and Venereology Department of Dr. Soetomo General Academic Hospital, Surabaya, from 2012 to 2014

\begin{tabular}{lrrrr}
\hline Source of transmission & \multicolumn{3}{c}{ Year } & Total (\%) \\
& $2012(\%)$ & $2013(\%)$ & $2014(\%)$ & $362(66,4)$ \\
\hline Family member & $126(64)$ & $131(68,2)$ & $105(67,3)$ & $49(9)$ \\
Boarding school & $8(4)$ & $27(14,1)$ & $14(9)$ & $11(2)$ \\
Neighbor & $2(1)$ & $1(0,5)$ & $8(5,1)$ & $123(22,6)$ \\
None & $61(31)$ & $33(17,2)$ & $29(18,6)$ & $545(100)$ \\
Total & $197(100)$ & $192(100)$ & $156(100)$ & \\
\hline
\end{tabular}

The most common site of complaint was the upper limb, totalling 329 patients $(60.37 \%)$, followed by truncal lesion in 308 patients $(56.61 \%)$, lower limb in 285 patients $(52.29 \%)$, between fingers in 238 patients $(43.67 \%)$, genitalia in 224 patients $(41.10 \%)$, buttocks in 88 patients $(16.15 \%)$, between toes in 83 patients $(15,23 \%)$, and the less common site-the scalp in 23 patients $(4.22 \%)$.

Table 5. The lesion sites of scabies patients in the Children Dermatology Division in the outpatient clinic of Dermatology and Venereology Department of Dr. Soetomo General Academic Hospital, Surabaya from 2012 to 2014

\begin{tabular}{lrrrr}
\hline & \multicolumn{3}{c}{ Year } & \\
\cline { 2 - 4 } Place of lesion & $2012(\%)$ & $2013(\%)$ & $2014(\%)$ & Total (\%) \\
\hline Scalp & & & & \\
Truncal & $8(4,10)$ & $7(3,65)$ & $8(5,13)$ & $23(4,22)$ \\
Wrist & $95(48,72)$ & $102(53,13)$ & $111(71,15)$ & $308(56,51)$ \\
Upper limb & $46(23,59)$ & $4(2,08)$ & $0(0)$ & $50(9,17)$ \\
Between the fingers & $125(64,10)$ & $93(48,44)$ & $111(71,15)$ & $329(60,37)$ \\
Lower limb & $87(44,62)$ & $100(52,08)$ & $51(32,69)$ & $238(43,67)$ \\
Between the toes & $100(51,28)$ & $84(43,75)$ & $101(64,74)$ & $285(52,29)$ \\
Genitalia & $44(22,56)$ & $23(11,98)$ & $16(10,26)$ & $83(15,23)$ \\
Buttocks & $83(42,56)$ & $86(44,79$ & $55(35,26)$ & $224(41,10)$ \\
\hline
\end{tabular}

(Note: a patient might present with more than one site of lesion)

The most common form of lesion in scabies patients at the Children Dermatology Division in the outpatient clinic of Dermatology and Venereology Department of Dr. Soetomo General Academic Hospital, Surabaya between 2012 and 2014 was papules found in 399 patients (73.2\%), followed by erythematous macula in 163 patients $(29.9 \%)$, and nodules in 11 patients $(2.0 \%)$.

Most scabies patients at the Children Dermatology Division in the outpatient clinic of the Dermatology and Venereology Department of Dr.
Soetomo General Academic Hospital, Surabaya between 2012 and 2014, were treated with topical scabicide therapy using permethrin 5\%, totalling 466 patients $(85.5 \%)$. Treatment using oral antihistamine (CTM) was found in 293 patients $(58.95 \%)$, oral antibiotic (Cloxacillin) in 87 patients (51.79\%), topical antibiotic (Fusidic Acid) in 54 patients (98.18\%). The most used combined therapy was permethrin, and oral antihistamine found in 271 patients $(49.7 \%)$. 
Table 6. The forms of lesion in scabies patients at the Children Dermatology Division in the outpatient clinic of Dermatology and Venereology Department of Dr. Soetomo General Academic Hospital, Surabaya from 2012 to 2014

\begin{tabular}{lrrrr}
\hline Lesion Morphology & \multicolumn{3}{c}{ Year } & Total (\%) \\
\cline { 2 - 4 } & $2012(\%)$ & $2013(\%)$ & $2014(\%)$ & \\
\hline Papules & $137(69.5)$ & $144(75.0)$ & $118(75.6)$ & $399(73.2)$ \\
\hline Pustules & $33(16.8)$ & $48(25.0)$ & $34(21.8)$ & $115(21.1)$ \\
\hline Erosion & $29(14.7)$ & $49(25.5)$ & $59(37.8)$ & $137(25.1)$ \\
\hline Crusts & $35(17.8)$ & $41(21.4)$ & $25(16.0)$ & $101(18.5)$ \\
\hline Squama & $9(4.6)$ & $18(9.4)$ & $34(21.8)$ & $61(11.2)$ \\
\hline Excoriation & $19(9.6)$ & $1(0.5)$ & $9(5.8)$ & $29(5.3)$ \\
\hline Vesicles & $14(7.1)$ & $16(8.3)$ & $13(8.3)$ & $43(7.9)$ \\
\hline Erythematous macula & $44(22.3)$ & $63(32.8)$ & $56(35.9)$ & $163(29.9)$ \\
\hline Nodules & $6(3.0)$ & $1(0.5)$ & $4(2.6)$ & $11(2.0)$ \\
\hline Papules + Pustules & $10(5.1)$ & $11(5.7)$ & $11(7.1)$ & $32(5.9)$ \\
\hline Papules + Erosion & $11(5.6)$ & $15(7.8)$ & $9(5.8)$ & $35(6.4)$ \\
\hline Papules + Macula & $11(5.6)$ & $12(6.3)$ & $9(5.8)$ & $32(5.9)$ \\
\hline Papules + pustules + erosion & $7(3.6)$ & $5(2.6)$ & $5(3.2)$ & $17(3.1)$ \\
\hline Papules + pustules + macula + erosion & $6(3.0)$ & $3(1.6)$ & $3(1.9)$ & $12(2.2)$ \\
\hline (Note: a partion
\end{tabular}

(Note: a patient might have more than one type of lesion)

Table 7. Combined therapy for scabies patients at the Children Dermatology Division in the outpatient clinic of Dermatology and Venereology Department of Dr. Soetomo General Academic Hospital, Surabaya, from 2012 to 2014

\begin{tabular}{|c|c|c|c|c|}
\hline \multirow[t]{2}{*}{ Therapy } & \multicolumn{3}{|c|}{ Year } & \multirow{2}{*}{$\begin{array}{c}\text { Total } \\
(\%)\end{array}$} \\
\hline & $\begin{array}{c}2012 \\
(\%)\end{array}$ & $\begin{array}{c}2013 \\
(\%)\end{array}$ & $\begin{array}{c}2014 \\
(\%)\end{array}$ & \\
\hline Permethrin + oral antihistamine & $126(64)$ & $95(48.7)$ & $50(32.1)$ & $271(49.7)$ \\
\hline Permethrin + topical antibiotic & $8(4.1)$ & $5(2.6)$ & $14(9)$ & $27(5)$ \\
\hline $\begin{array}{l}\text { Permethrin }+ \text { oral antihistamine }+ \text { topical } \\
\text { antibiotic }\end{array}$ & $6(3)$ & $5(2.6)$ & $12(7.7)$ & $23(4.2)$ \\
\hline
\end{tabular}

\section{DISCUSSION}

The majority of patients were from 5-14 years old age group; there were 377 patients (69\%) in this group. Corresponding to Kaur and Nadeswary's study in Malaysia, scabies is most commonly found in children aged 5-9 years old. ${ }^{7}$ Lassa et al. arranged a prevalence epidemiologic study in England and they found that the highest prevalence was in 10-19 years old group. ${ }^{10}$ This might be caused by inadequate selfhygiene behavior in children. Moreover, children between 5-14 years old are the most social and they do a lot of outdoor activities, making them more vulnerable to this disease.

There were 341 male $(62.6 \%)$ and 204 female (37.4\%) patients, and the ratio was $1.67: 1$. This was likely related to a particular behavior that boys tend to less concern about hygiene and they do more outdoor activities. In line with the previous study conducted by Paramita at the Children Dermatology Division in the outpatient clinic of the Dermatology and
Venereology Department of Dr. Soetomo General Academic Hospital between 2009 and 2011. They found that $63.8 \%$ of patients were male and $36.2 \%$ female. Lassa et al., in their study conducted in England from 1997 to 2005, found that there were more female scabies patients than male. ${ }^{10}$ Marks et al., in a study conducted in Salomon Islands, also found that there were more female patients than male. ${ }^{11}$ An epidemiologic study indicated that the prevalence of scabies is not affected by sex, race, age, or socioeconomic status. ${ }^{1}$

A large numbers of scabies patients, totalling up to 383 patients $(70.28 \%$ ), at the Children Dermatology Division in the outpatient clinic of Dermatology and Venereology Department of Dr. Soetomo General Academic Hospital between 2012 and 2014 presented with itchiness as their main complaint and it worsens at night. This finding corresponds with a study conducted by Paramita at the Children Dermatology Division in the outpatient clinic of the Dermatology 
and Venereology Department of Dr. Soetomo General Academic Hospital between 2009 and 2011. The study found that most patients, which were 170 patients $(60.9 \%)$, had a history of a similar complaint within the family members. This confirms the theory that close physical contact mediates scabies transmission; therefore it is common within family members. ${ }^{1}$

Most lesions were found on the upper limbs of 329 patients $(60.37 \%)$ followed by truncal lesion of 308 patients $(56.61 \%)$, lower limbs lesion of 285 patients $(52.29 \%)$, between fingers of 238 patients (43.67\%), genitalia of 224 patients $(41.10 \%)$, buttocks of 88 patients $(1615 \%)$, between toes of 83 patients (15.23\%), and the less common site, scalps of 23 patients $(4.22 \%)$. This was in accordance with the theory that states scabies has a predilection on the hands, between the fingers, elbow, shoulder, genital, including the penis, lower leg, mainly the ankle, scrotum in males, and chest in females. ${ }^{1,6,12}$ Those body parts specifically have thinner skin, which scabies mites favor. In a healthy adult, a head and neck lesion is uncommon. However, scabies may occur on any parts of the body of infants, elders, and people with weak immune. ${ }^{6}$

Morphologically, papules are the most common lesions; they are found in 399 patients (73.2\%); followed by erythematous macula in 163 patients $(29.9 \%)$, and nodules in 11 patients $(2.0 \%)$. The finding was in accordance with the theory that states scabies occurs in the form of papules, vesicles, nodules, excoriations, and burrows. .,7 $^{4}$

Most scabies patients, which were 338 patients $(62.02 \%)$, at the Children Dermatology Division in the outpatient clinic of Dermatology and Venereology Department of Dr. Soetomo General Academic Hospital had scabies as the sole diagnosis followed by scabies with a secondary infection found in 167 patients $(30.64 \%)$. Additionally, there were 115 patients $(21.1 \%)$ had pustular lesion. This was in accordance with the literature, stating that secondary infection may occur alongside scabies, and it is mainly caused by Staphylococcus aureus and Streptococcus pyogenes. The infection may worsen into an abscess, cellulitis, necrotizing fasciitis, septicaemia, renal disease, and rheumatic heart disease. ${ }^{13}$ Scabies with atopic dermatitis was the third most common diagnosis and it requires more management as it may vary in clinical presentation. Furthermore, topical or oral steroids were usually prescribed as additional therapy.

The most common combined therapy, which was found in 271 patients (49.7\%), was permethrin and an oral antihistamine. A study conducted by Paramita at the Children Dermatology Division in the outpatient clinic of the Dermatology and Venereology Department of Dr. Soetomo General Academic Hospital between 2009 and 2011 found that permethrin as a topical scabicide was the main therapy prescribed to 257 patients (97.3\%). Another survey by Gabriel at Prof. Dr. R. D. Kandou Regional Public Hospital, Manado, in 2013 found that that therapy mainly consisted of permethrin 5\% combined with antibiotics and antihistamines $(83.33 \%){ }^{14}$

A randomized control trial by Cochrane collaboration summed up that permethrin is the most effective agent for scabies. ${ }^{3,6}$ The itchiness can be handled by antihistamines such as chlorpheniramine, hydroxycin, diphenhydramine, dexchlorpheniramine. ${ }^{7}$ Systemic or topical antibiotics may be used in the presence of secondary infection. ${ }^{9}$

\section{References}

1. Walton SF, Currie BJ. Problems in diagnosing scabies, a global disease in human and animal populations. Clin Microbiol Rev 2007; 20(2): 268-79.

2. Engelman D, Kiang K, Chosidow O, McCarthy J, Fuller C, Lammie P et al. Toward the global control of human scabies: introducing the international alliance for the control of scabies. Plos Nel Trop Dis 2013; 7(8):1-4.

3. Paramita K, Sawitri. Profil skabies pada anak. Berkala Ilmu Kesehatan Kuit dan Kelamin 2015; 27(1): 41-6.

4. Chosidow O. Scabies. N Eng J Med 2006; 354(16):1718-26.

5. Monsel G, Delaunay $\mathrm{P}$, Chosidow O. Arthropods. In: Rook's Textbook of Dermatology. $9^{\text {th }}$ ed. Oxford: Wiley-Blackweel; 2016. p. 34, 39-45.

6. Wheat $\mathrm{CM}$, Burkhart $\mathrm{CN}$, Burkhart $\mathrm{CG}$ and Cohen BA. Scabies, other mites and pediculosis. In: Kang S, Amagai M, Bruckner AL, Enk AH, Margolis DJ, McMichael AJ et al, editors. Fitzpatrick's Dermatology. $9^{\text {th }}$ ed. New York: McGraw-Hill, 2019. p. 3274-86.

7. Ministry of Health Malaysia. Guideline for Management of scabies in adults and children; 2015 [cited 2016 Nov 21]. Available from: URL: http://www.moh.gov.my/index.php/file_manager /dl_item.

8. Boedihardja SA and Handoko RP. Skabies. In: Ilmu penyakit kulit dan kelamin. Edisi keenam. Jakarta: FKUI 2010. p. 137-40.

9. Thomas J, Peterson GM, Walton SF, Carson CF, Naunton M, Baby KE. Scabies: an ancient global 
disease with a need for new therapies. BMC Infectious Disease 2015; 15(7):1-6.

10. Lassa S, Campbell MJ, and Bennett CE. Epidemiology of scabies prevalence in the U.K form general practice records. British Association of Dermatologists 2011; 164(6): 1329-34.

11. Marks M, Taotao-Wini B, Satorara L, Engelman D, Nasi T, Mabey DC, etc. Long term control of scabies fifteen years, after an intensive treatment program. PloS Negl Trop Dis 2015; 9(12):1-9.

12. Mounsey KE, McCarthy JS. Treatment and control of scabies. Curr Opin Infect Dis 2013; 26(2):1-6.
13. Romani L, Steer AC, Whitfield MJ, Kaldor JM. Prevalence of scabies and impetigo worldwide: a systematic review. Lancet Infect Dis 2015; 15(8):960-7.

14. Gabriel JS, Suling PL, Pandaleke HEJ. Profil skabies di poliklinik kulit dan kelamin RSUP Prof. Dr. R. D. Kandao Manado periode JanuariDesember 2013. Jurnal e-Clinic 2016; 4(2):1-7.

15. Fauzia M, Zulkarnain I. Pola penyakit kulit penderita anak di instalasi rawat inap penyakit kulit dan kelamin RSUD Dr. Soetomo Surabaya periode 2002-2006. BIKKK 2007; 19(3):183-96. 